Чекановского - 0,7) на территории кампуса Тьенху Наньчанского университета КНР.

\section{Список использованной литературы}

1.Guo Ying Rong, Shao Ming Qin, Ye Shui Song Preliminary Study on the Bird Diversity Surrounding Nanchang Univercity - Journal of Anhui Agriculture Sciences, 38(13), 2010. P. 6739 - 6740.

УДК $612: 57.017 .64$

ББК 28.83

ОКСО 050102 Биология

ГРНТИ 34.4176 .29
2.Wang Jie, Wang Pao She, Luo Zheng Qi Dictionary of the Yangtze River. - Wuhan Press, 1997. P. 16.

3.Равкин Ю.С., Доброхотов Б.П. К методике учета птиц лесных ландшафтов во внегнездовое время. // Организация и методы учета птиц и вредных грызунов. - М., 1963 - С. 130-136.

СИСТЕМА РОСТА И РАЗВИТИЯ ТЕЛА ЧЕЛОВЕКА

DOI: $10.31618 /$ ESU.2413-9335.2020.3.71.588

Мазко Галина Александровна

биолог,

Уральский Федеральный Университет имени Б.Н. Ельцинна, Институт естественных наук.

Россия, Свердловская область, г. Дегтярск, ул Калинина д № 66, кв 7 сот. 89502018774

\title{
THE SYSTEM OF GROWTH AND DEVELOPMENT OF THE HUMAN BODY
}

\author{
Mazko Galina Aleksandrovna \\ biologist, \\ Ural Federal University named after B.N. Yeltsin, \\ Institute of Natural Sciences. \\ Russia, Sverdlovsk Region, Degtyarsk, \\ Kalinin str., No. 66, apt. 89502018774
}

\begin{abstract}
АННОТАЦИЯ
Создана система роста и развития тела человека с модуля «т» до возраста новорожденного и возраста долгожителя для мужской и женской фигуры.

Модуль «m» - оплодотворенная яйцеклетка человека с двойным зарядом энергии делится, умножая массу тела и энергии в геометрической прогрессии, образует в разных количествах формулы роста фигур, превращается в формы тела человека.

После закладки модуля «т»» рост и развитие тела человека идет от отметки «Промежность» вверх и вниз, причем вверх интенсивнее.

В возрасте 12-15 лет тело человека вступает в стадию «Созревание».

С этого периода мерка «m» (расстояние между складкой кожи на верхней ногтевой фаланге мизинца руки и верхушечной точкой кожи мизинца) на теле человека остается неизменной до конца жизни.

Рост (длина и масса тела) продолжается до18 -25 лет. После этого происходит лишь обновление клеток за счет окислительно- восстановительных реакций. Развитие тела происходит в течение всей его жизни.

\section{ANNOTATION}

A system for the growth and development of the human body from the " $m$ " module to the age of the newborn and the age of the long-liver for the male and female figures has been created. Module "m" - a fertilized human egg with a double charge of energy is divided, multiplying the mass of the body and energy exponentially, forms in different quantities the growth formulas of the figures, turns into the shape of the human body. After laying the " $m$ " module, the growth and development of the human body goes from the "Crotch" mark up and down, and up more intensively. At the age of 12-15 years, the human body enters the stage of "ripening". From this period, the " $\mathrm{m}$ " measurement (the distance between the skin fold on the upper nail phalanx of the little finger of the hand and the apical point of the skin of the little finger) on the human body remains unchanged until the end of life. Growth (length and body weight) lasts up to 18-25 years. After this, only cell renewal occurs due to redox reactions. The development of the body occurs throughout its life.
\end{abstract}

Ключевые слова: мерка «т», О пястья, О ладони, индекс роста, формула оболочки тела.

Keywords: measurement "m", O metacarpus, O palm, growth index, body shell formula, 
Система роста и развития тела человека. Фигура женская.

\begin{tabular}{|c|c|c|c|c|c|c|c|c|c|c|c|c|}
\hline $\begin{array}{c}\text { голо } \\
\text { ва }\end{array}$ & $\begin{array}{l}\text { ше } \\
\text { я }\end{array}$ & грудь & $\begin{array}{c}\text { тали } \\
\text { я }\end{array}$ & таз & $\begin{array}{c}\text { проме } \\
\text { ж }\end{array}$ & $\begin{array}{c}\text { колен } \\
\text { o }\end{array}$ & икра & $\begin{array}{c}\text { лодыж } \\
\text { ка }\end{array}$ & $\begin{array}{c}\text { ступ } \\
\text { ня }\end{array}$ & $\begin{array}{c}\text { Форму } \\
\text { ла } \\
\text { роста }\end{array}$ & $\begin{array}{c}\text { Инде } \\
\text { кс } \\
\text { роста } \\
\end{array}$ & рост \\
\hline & & & & & $\mathrm{m}$ & & & & & & & \\
\hline & & & & $\mathrm{m}$ & $\mathrm{m}$ & & & & & & & \\
\hline & & & $\mathrm{m}$ & $\mathrm{m}$ & $\mathrm{m}$ & $\mathrm{m}$ & & & & & & \\
\hline & & $\mathrm{m}$ & $\mathrm{m}$ & $\mathrm{m}$ & $\mathrm{m}$ & $\mathrm{m}$ & $\mathrm{m}$ & & & & & \\
\hline & $\mathrm{m}$ & $\mathrm{m}$ & $\mathrm{m}$ & $\mathrm{m}$ & $\mathrm{m}$ & $\mathrm{m}$ & $\mathrm{m}$ & $\mathrm{m}$ & & & & 1месяц \\
\hline $\mathrm{m}$ & $\mathrm{m}$ & $\mathrm{m}$ & $\mathrm{m}$ & $\mathrm{m}$ & $\mathrm{m}$ & $\mathrm{m}$ & $\mathrm{m}$ & $\mathrm{m}$ & $\mathrm{m}$ & 1 & $\mathrm{~m}$ & 2 \\
\hline $2 \mathrm{~m}$ & $2 \mathrm{~m}$ & $2 \mathrm{~m}$ & $2 \mathrm{~m}$ & $2 \mathrm{~m}$ & $2 \mathrm{~m}$ & $2 \mathrm{~m}$ & $2 \mathrm{~m}$ & $2 \mathrm{~m}$ & $2 \mathrm{~m}$ & 2 & $2 \mathrm{~m}$ & 3 \\
\hline $4 \mathrm{~m}$ & $2 \mathrm{~m}$ & $3 \mathrm{~m}$ & $3 \mathrm{~m}$ & $3 \mathrm{~m}$ & $3 m$ & $2 \mathrm{~m}$ & $2 \mathrm{~m}$ & $3 \mathrm{~m}$ & $3 \mathrm{~m}$ & 2,8 & $2,8 \mathrm{~m}$ & 4 \\
\hline $6 \mathrm{~m}$ & $2 \mathrm{~m}$ & $4 \mathrm{~m}$ & $4 \mathrm{~m}$ & $4 \mathrm{~m}$ & $4 \mathrm{~m}$ & $2 \mathrm{~m}$ & $2 \mathrm{~m}$ & $3 \mathrm{~m}$ & $3 \mathrm{~m}$ & 3,4 & $3,4 \mathrm{~m}$ & 5 \\
\hline $10 \mathrm{~m}$ & $2 \mathrm{~m}$ & $4 \mathrm{~m}$ & $4 \mathrm{~m}$ & $5 \mathrm{~m}$ & $5 \mathrm{~m}$ & $2 \mathrm{~m}$ & $2 \mathrm{~m}$ & $3 \mathrm{~m}$ & $3 \mathrm{~m}$ & 3,9 & $3,9 \mathrm{~m}$ & 6 \\
\hline $10 \mathrm{~m}$ & $2 \mathrm{~m}$ & $4 \mathrm{~m}$ & $4 \mathrm{~m}$ & $5 \mathrm{~m}$ & $5 \mathrm{~m}$ & $2 \mathrm{~m}$ & $2 \mathrm{~m}$ & $3 \mathrm{~m}$ & $3 \mathrm{~m}$ & 3,95 & $3,95 \mathrm{~m}$ & 7 \\
\hline $10 \mathrm{~m}$ & $2 \mathrm{~m}$ & $4 \mathrm{~m}$ & $4 \mathrm{~m}$ & $5 \mathrm{~m}$ & $5 \mathrm{~m}$ & $2 \mathrm{~m}$ & $2 \mathrm{~m}$ & $3 \mathrm{~m}$ & $3 \mathrm{~m}$ & 5 & $5 \mathrm{~m}$ & 8 \\
\hline $10 \mathrm{~m}$ & $2 \mathrm{~m}$ & $4 \mathrm{~m}$ & $4 \mathrm{~m}$ & $5 \mathrm{~m}$ & $5 \mathrm{~m}$ & $2 \mathrm{~m}$ & $2 \mathrm{~m}$ & $3 \mathrm{~m}$ & $3 \mathrm{~m}$ & 5 & $5 \mathrm{~m}$ & 9 \\
\hline $9 m$ & $2 \mathrm{~m}$ & $5 \mathrm{~m}$ & $5 \mathrm{~m}$ & $5 \mathrm{~m}$ & $5 \mathrm{~m}$ & $3 \mathrm{~m}$ & $3 \mathrm{~m}$ & $4 \mathrm{~m}$ & $3 \mathrm{~m}$ & 5,37 & $5,37 \mathrm{~m}$ & $\begin{array}{c}\text { Новоро } \\
\text { жд } \\
\end{array}$ \\
\hline $9 \mathrm{~m}$ & $2 \mathrm{~m}$ & $5 \mathrm{~m}$ & $5 \mathrm{~m}$ & $5 \mathrm{~m}$ & $5 \mathrm{~m}$ & $4 \mathrm{~m}$ & $4 \mathrm{~m}$ & $5 \mathrm{~m}$ & $3 \mathrm{~m}$ & 5,75 & $5,75 \mathrm{~m}$ & Грудной \\
\hline $9 \mathrm{~m}$ & $2 \mathrm{~m}$ & $5 \mathrm{~m}$ & $5 \mathrm{~m}$ & $5 \mathrm{~m}$ & $5 \mathrm{~m}$ & $5 \mathrm{~m}$ & $5 \mathrm{~m}$ & $6 \mathrm{~m}$ & $3 \mathrm{~m}$ & 6,1 & $6,1 \mathrm{~m}$ & $\begin{array}{c}\text { Раннее } \\
\text { детс. }\end{array}$ \\
\hline $8 \mathrm{~m}$ & $2 \mathrm{~m}$ & $5 \mathrm{~m}$ & $5 \mathrm{~m}$ & $5,5 \mathrm{~m}$ & $5 \mathrm{~m}$ & $6 \mathrm{~m}$ & $6 \mathrm{~m}$ & $6,5 \mathrm{~m}$ & $3 \mathrm{~m}$ & 6,5 & $6,5 \mathrm{~m}$ & $\begin{array}{c}\text { I период } \\
\text { дет }\end{array}$ \\
\hline $8 \mathrm{~m}$ & $2 \mathrm{~m}$ & $5,5 \mathrm{~m}$ & $5,5 \mathrm{~m}$ & $6 \mathrm{~m}$ & $5 \mathrm{~m}$ & $6,5 \mathrm{~m}$ & $6,5 \mathrm{~m}$ & $7 \mathrm{~m}$ & $3 \mathrm{~m}$ & 6,87 & $6,87 \mathrm{~m}$ & $\begin{array}{c}\text { II } \\
\text { пер.детс } \\
\text { т } \\
\end{array}$ \\
\hline $8 \mathrm{~m}$ & $2 \mathrm{~m}$ & $6 \mathrm{~m}$ & $6 \mathrm{~m}$ & $6,5 \mathrm{~m}$ & $5 \mathrm{~m}$ & $7 \mathrm{~m}$ & $7 \mathrm{~m}$ & $7,5 \mathrm{~m}$ & $3 \mathrm{~m}$ & 7,24 & $7,24 \mathrm{~m}$ & $\begin{array}{c}\text { Подрост } \\
\text { ок }\end{array}$ \\
\hline $8 \mathrm{~m}$ & $2 \mathrm{~m}$ & $6,5 \mathrm{~m}$ & $6,5 \mathrm{~m}$ & $7 \mathrm{~m}$ & $5 \mathrm{~m}$ & $7,5 \mathrm{~m}$ & $7,5 \mathrm{~m}$ & $7,5 \mathrm{~m}$ & $3 \mathrm{~m}$ & 7,62 & $7,62 \mathrm{~m}$ & $\begin{array}{c}\text { I } \\
\text { Юношес } \\
\text { к. } \\
\end{array}$ \\
\hline $8 \mathrm{~m}$ & $2 \mathrm{~m}$ & $7 \mathrm{~m}$ & $7 \mathrm{~m}$ & $8 \mathrm{~m}$ & $5 \mathrm{~m}$ & $8 \mathrm{~m}$ & $8 m$ & $8 \mathrm{~m}$ & $3 \mathrm{~m}$ & 7,9 & $7,9 \mathrm{~m}$ & $\begin{array}{c}\text { II } \\
\text { Взрослы } \\
\text { й }\end{array}$ \\
\hline $8 \mathrm{~m}$ & $2 \mathrm{~m}$ & $7,5 \mathrm{~m}$ & $7,5 \mathrm{~m}$ & $\begin{array}{c}8,25 \\
\mathrm{~m}\end{array}$ & $5 \mathrm{~m}$ & $\begin{array}{c}8,25 \\
\mathrm{~m}\end{array}$ & $\begin{array}{c}8,25 \\
\mathrm{~m}\end{array}$ & $8,25 \mathrm{~m}$ & $3 \mathrm{~m}$ & 8,25 & $8,25 \mathrm{~m}$ & III \\
\hline $8 \mathrm{~m}$ & $2 \mathrm{~m}$ & $8 \mathrm{~m}$ & $8 \mathrm{~m}$ & $8,5 \mathrm{~m}$ & $5 \mathrm{~m}$ & $8,5 \mathrm{~m}$ & $8,5 \mathrm{~m}$ & $8,5 \mathrm{~m}$ & $3 \mathrm{~m}$ & 8,5 & $8,5 \mathrm{~m}$ & IY \\
\hline $8 \mathrm{~m}$ & $2 \mathrm{~m}$ & $8 \mathrm{~m}$ & $8 \mathrm{~m}$ & $\begin{array}{c}8,75 \\
\mathrm{~m}\end{array}$ & $5 \mathrm{~m}$ & $\begin{array}{c}8,75 \\
\mathrm{~m}\end{array}$ & $\begin{array}{c}8,75 \\
\mathrm{~m} \\
\end{array}$ & $8.75 \mathrm{~m}$ & $3 \mathrm{~m}$ & 8,75 & $8,75 \mathrm{~m}$ & $\mathrm{Y}$ \\
\hline $8 \mathrm{~m}$ & $2 \mathrm{~m}$ & $8,5 \mathrm{~m}$ & $8,5 \mathrm{~m}$ & $9 \mathrm{~m}$ & $6 \mathrm{~m}$ & $9 \mathrm{~m}$ & $9 \mathrm{~m}$ & $9 \mathrm{~m}$ & $3 \mathrm{~m}$ & 9 & $9 \mathrm{~m}$ & YI \\
\hline $8 \mathrm{~m}$ & $2 \mathrm{~m}$ & $\begin{array}{c}8,755 \\
\mathrm{~m}\end{array}$ & $\begin{array}{c}8,75 \\
\mathrm{~m}\end{array}$ & 9,25 & $6,5 \mathrm{~m}$ & $\begin{array}{c}9,25 \\
\mathrm{~m}\end{array}$ & $\begin{array}{c}9,25 \\
\mathrm{~m}\end{array}$ & $9,25 \mathrm{~m}$ & $3 m$ & 9,25 & $9,25 \mathrm{~m}$ & YII \\
\hline $8 \mathrm{~m}$ & $2 \mathrm{~m}$ & $9 \mathrm{~m}$ & $9 \mathrm{~m}$ & 9,5 & $7 \mathrm{~m}$ & $9,5 \mathrm{~m}$ & $9,5 \mathrm{~m}$ & $9,5 \mathrm{~m}$ & $3 \mathrm{~m}$ & 9,5 & $9,5 \mathrm{~m}$ & YIII \\
\hline $8 \mathrm{~m}$ & $2 \mathrm{~m}$ & $9,25 \mathrm{~m}$ & $\begin{array}{c}9,25 \\
\mathrm{~m} \\
\end{array}$ & 9,75 & $7,5 \mathrm{~m}$ & $\begin{array}{c}9,75 \\
\mathrm{~m}\end{array}$ & $\begin{array}{c}9,75 \\
\mathrm{~m}\end{array}$ & $9,75 \mathrm{~m}$ & $3 \mathrm{~m}$ & 9,75 & $9,75 \mathrm{~m}$ & IX \\
\hline $8 \mathrm{~m}$ & $2 \mathrm{~m}$ & $9,5 \mathrm{~m}$ & $9,5 \mathrm{~m}$ & $10 \mathrm{~m}$ & $8 \mathrm{~m}$ & $10 \mathrm{~m}$ & $10 \mathrm{~m}$ & $10 \mathrm{~m}$ & $3 \mathrm{~m}$ & 10 & $10 \mathrm{~m}$ & $X$ \\
\hline \multicolumn{13}{|c|}{ Фигура мужская. } \\
\hline $\begin{array}{c}\text { голо } \\
\text { ва }\end{array}$ & $\begin{array}{l}\text { ше } \\
\text { я }\end{array}$ & $\begin{array}{c}\text { груд } \\
\text { ь }\end{array}$ & $\begin{array}{c}\text { тали } \\
\text { я }\end{array}$ & таз & $\begin{array}{c}\text { проме } \\
\text { ж }\end{array}$ & $\begin{array}{c}\text { колен } \\
\text { о }\end{array}$ & икра & $\begin{array}{c}\text { лодыж } \\
\text { ка }\end{array}$ & $\begin{array}{c}\text { ступ } \\
\text { ня }\end{array}$ & $\begin{array}{c}\text { Форму } \\
\text { ла } \\
\text { роста } \\
\end{array}$ & $\begin{array}{c}\text { Инде } \\
\text { кс } \\
\text { роста } \\
\end{array}$ & рост \\
\hline & & & & & $\mathrm{m}$ & & & & & & & \\
\hline & & & & $\mathrm{m}$ & $\mathrm{m}$ & & & & & & & \\
\hline & & & $\mathrm{m}$ & $\mathrm{m}$ & $\mathrm{m}$ & $\mathrm{m}$ & & & & & & \\
\hline & & $\mathrm{m}$ & $\mathrm{m}$ & $\mathrm{m}$ & $\mathrm{m}$ & $\mathrm{m}$ & $\mathrm{m}$ & & & & & \\
\hline & $\mathrm{m}$ & $\mathrm{m}$ & $\mathrm{m}$ & $\mathrm{m}$ & $\mathrm{m}$ & $\mathrm{m}$ & $\mathrm{m}$ & $\mathrm{m}$ & & & & 1месяц \\
\hline $\mathrm{m}$ & $\mathrm{m}$ & $\mathrm{m}$ & $\mathrm{m}$ & $\mathrm{m}$ & $\mathrm{m}$ & $\mathrm{m}$ & $\mathrm{m}$ & $\mathrm{m}$ & $\mathrm{m}$ & 1 & $\mathrm{~m}$ & 2 \\
\hline $2 \mathrm{~m}$ & $2 \mathrm{~m}$ & $2 \mathrm{~m}$ & $2 \mathrm{~m}$ & $2 \mathrm{~m}$ & $2 \mathrm{~m}$ & $2 \mathrm{~m}$ & $2 \mathrm{~m}$ & $2 \mathrm{~m}$ & $2 \mathrm{~m}$ & 2 & $2 \mathrm{~m}$ & 3 \\
\hline $4 \mathrm{~m}$ & $2 \mathrm{~m}$ & $3 \mathrm{~m}$ & $3 \mathrm{~m}$ & $3 \mathrm{~m}$ & $3 \mathrm{~m}$ & $2 \mathrm{~m}$ & $2 \mathrm{~m}$ & $3 \mathrm{~m}$ & $3 \mathrm{~m}$ & 2,8 & $2,8 \mathrm{~m}$ & 4 \\
\hline $6 \mathrm{~m}$ & $2 \mathrm{~m}$ & $4 \mathrm{~m}$ & $4 \mathrm{~m}$ & $4 \mathrm{~m}$ & $4 \mathrm{~m}$ & $2 \mathrm{~m}$ & $2 \mathrm{~m}$ & $3 \mathrm{~m}$ & $3 \mathrm{~m}$ & 3,4 & $3,4 \mathrm{~m}$ & 5 \\
\hline
\end{tabular}




\begin{tabular}{|c|c|c|c|c|c|c|c|c|c|c|c|c|}
\hline $10 \mathrm{~m}$ & $2 \mathrm{~m}$ & $4 \mathrm{~m}$ & $4 \mathrm{~m}$ & $5 \mathrm{~m}$ & $5 \mathrm{~m}$ & $2 \mathrm{~m}$ & $2 \mathrm{~m}$ & $3 \mathrm{~m}$ & $3 \mathrm{~m}$ & 3,9 & $3,9 \mathrm{~m}$ & 6 \\
\hline $10 \mathrm{~m}$ & $2 \mathrm{~m}$ & $4 \mathrm{~m}$ & $4 \mathrm{~m}$ & $5 \mathrm{~m}$ & $5 \mathrm{~m}$ & $2 \mathrm{~m}$ & $2 \mathrm{~m}$ & $3 \mathrm{~m}$ & $3 \mathrm{~m}$ & 3,95 & $3,95 \mathrm{~m}$ & 7 \\
\hline $10 \mathrm{~m}$ & $2 m$ & $4 m$ & $4 m$ & $5 \mathrm{~m}$ & $5 \mathrm{~m}$ & $2 \mathrm{~m}$ & $2 \mathrm{~m}$ & $3 m$ & $3 m$ & 5 & $5 \mathrm{~m}$ & 8 \\
\hline $10 \mathrm{~m}$ & $2 \mathrm{~m}$ & $4 \mathrm{~m}$ & $4 \mathrm{~m}$ & $5 \mathrm{~m}$ & $5 \mathrm{~m}$ & $2 \mathrm{~m}$ & $2 \mathrm{~m}$ & $3 \mathrm{~m}$ & $3 \mathrm{~m}$ & 5 & $5 \mathrm{~m}$ & 9 \\
\hline $9 \mathrm{~m}$ & $2 \mathrm{~m}$ & $5 \mathrm{~m}$ & $5 \mathrm{~m}$ & $5 \mathrm{~m}$ & $5 \mathrm{~m}$ & $3 \mathrm{~m}$ & $3 \mathrm{~m}$ & $4 \mathrm{~m}$ & $3 \mathrm{~m}$ & 5,37 & $5,37 \mathrm{~m}$ & $\begin{array}{c}\text { Новорож } \\
\text { д. }\end{array}$ \\
\hline $9 \mathrm{~m}$ & $2 \mathrm{~m}$ & $5 \mathrm{~m}$ & $5 \mathrm{~m}$ & $5 \mathrm{~m}$ & $5 \mathrm{~m}$ & $4 \mathrm{~m}$ & $4 \mathrm{~m}$ & $5 \mathrm{~m}$ & $3 \mathrm{~m}$ & 5,75 & $5,75 \mathrm{~m}$ & Грудной \\
\hline $9 \mathrm{~m}$ & $2 \mathrm{~m}$ & $5 \mathrm{~m}$ & $5 \mathrm{~m}$ & $5 \mathrm{~m}$ & $5 \mathrm{~m}$ & $5 \mathrm{~m}$ & $5 \mathrm{~m}$ & $6 \mathrm{~m}$ & $3 \mathrm{~m}$ & 6,1 & $6,1 \mathrm{~m}$ & $\begin{array}{c}\text { Раннее } \\
\text { детс }\end{array}$ \\
\hline $8 \mathrm{~m}$ & $2 \mathrm{~m}$ & $5 \mathrm{~m}$ & $5 \mathrm{~m}$ & $5,5 \mathrm{~m}$ & $5 \mathrm{~m}$ & $6 \mathrm{~m}$ & $6 \mathrm{~m}$ & $6,5 \mathrm{~m}$ & $3 \mathrm{~m}$ & 6,5 & $6,5 \mathrm{~m}$ & $\begin{array}{c}\text { I период } \\
\text { дет }\end{array}$ \\
\hline $8 \mathrm{~m}$ & $2 \mathrm{~m}$ & $5,5 \mathrm{~m}$ & $5,5 \mathrm{~m}$ & $6 \mathrm{~m}$ & $5 \mathrm{~m}$ & $6,5 \mathrm{~m}$ & $6,5 \mathrm{~m}$ & $7 \mathrm{~m}$ & $3 \mathrm{~m}$ & 6,87 & $6,87 \mathrm{~m}$ & $\begin{array}{l}\text { II пер. } \\
\text { детст }\end{array}$ \\
\hline $8 \mathrm{~m}$ & $2 \mathrm{~m}$ & $6 \mathrm{~m}$ & $6 \mathrm{~m}$ & $6,5 \mathrm{~m}$ & $5 \mathrm{~m}$ & $7 \mathrm{~m}$ & $7 \mathrm{~m}$ & $7,5 \mathrm{~m}$ & $3 \mathrm{~m}$ & 7,24 & $7,24 \mathrm{~m}$ & $\begin{array}{c}\text { Подрост } \\
\text { ок }\end{array}$ \\
\hline $8 \mathrm{~m}$ & $2 \mathrm{~m}$ & $7 \mathrm{~m}$ & $7 \mathrm{~m}$ & $6,5 \mathrm{~m}$ & $5 \mathrm{~m}$ & $7 \mathrm{~m}$ & $7,5 \mathrm{~m}$ & $7,5 \mathrm{~m}$ & $3 \mathrm{~m}$ & 7,62 & $7,62 \mathrm{~m}$ & $\begin{array}{c}\mathrm{I} \\
\text { Юношес } \\
\text { к }\end{array}$ \\
\hline $8 \mathrm{~m}$ & $2 \mathrm{~m}$ & $8 \mathrm{~m}$ & $8 \mathrm{~m}$ & $6,6 \mathrm{~m}$ & $5 \mathrm{~m}$ & $7,7 \mathrm{~m}$ & $7,7 \mathrm{~m}$ & $7,7 \mathrm{~m}$ & $3 \mathrm{~m}$ & 7,9 & $7,9 \mathrm{~m}$ & $\begin{array}{c}\text { IIВзросл } \\
\text { ый }\end{array}$ \\
\hline $8 \mathrm{~m}$ & $2 \mathrm{~m}$ & $\begin{array}{c}8,25 \\
\mathrm{~m} \\
\end{array}$ & $\begin{array}{c}8,25 \\
\mathrm{~m} \\
\end{array}$ & $\begin{array}{c}7,25 \\
\mathrm{~m} \\
\end{array}$ & $5 \mathrm{~m}$ & $\begin{array}{c}8,25 \\
\mathrm{~m} \\
\end{array}$ & $\begin{array}{c}8,25 \\
\mathrm{~m} \\
\end{array}$ & $8,25 \mathrm{~m}$ & $3 \mathrm{~m}$ & 8,25 & $8,25 \mathrm{~m}$ & III \\
\hline $8 \mathrm{~m}$ & $2 \mathrm{~m}$ & $8,5 \mathrm{~m}$ & $8,5 \mathrm{~m}$ & $7,5 \mathrm{~m}$ & $5 \mathrm{~m}$ & $8,5 \mathrm{~m}$ & $8,5 \mathrm{~m}$ & $8,5 \mathrm{~m}$ & $3 \mathrm{~m}$ & 8,5 & $8,5 \mathrm{~m}$ & IY \\
\hline $8 \mathrm{~m}$ & $2 \mathrm{~m}$ & $\begin{array}{c}8,75 \\
\mathrm{~m}\end{array}$ & $\begin{array}{c}8,75 \\
\mathrm{~m}\end{array}$ & $\begin{array}{c}7,75 \\
\mathrm{~m}\end{array}$ & $6 \mathrm{~m}$ & $\begin{array}{c}8,75 \\
\mathrm{~m}\end{array}$ & $\begin{array}{c}8,75 \\
\mathrm{~m}\end{array}$ & $8.75 \mathrm{~m}$ & $3 \mathrm{~m}$ & 8,75 & $8,75 \mathrm{~m}$ & $\mathrm{Y}$ \\
\hline $8 \mathrm{~m}$ & $2 \mathrm{~m}$ & $9 \mathrm{~m}$ & $9 \mathrm{~m}$ & $8 \mathrm{~m}$ & $6,5 \mathrm{~m}$ & $9 \mathrm{~m}$ & $9 \mathrm{~m}$ & $9 \mathrm{~m}$ & $3 \mathrm{~m}$ & 9 & $9 \mathrm{~m}$ & YI \\
\hline $8 \mathrm{~m}$ & $2 \mathrm{~m}$ & $\begin{array}{c}9,25 \\
\mathrm{~m}\end{array}$ & $\begin{array}{c}9,25 \\
\mathrm{~m}\end{array}$ & 8,25 & $7 \mathrm{~m}$ & $\begin{array}{c}9,25 \\
\mathrm{~m} \\
\end{array}$ & $\begin{array}{c}9,25 \\
\mathrm{~m} \\
\end{array}$ & $9,25 \mathrm{~m}$ & $3 \mathrm{~m}$ & 9,25 & $9,25 \mathrm{~m}$ & YII \\
\hline $8 \mathrm{~m}$ & $2 \mathrm{~m}$ & $9,5 \mathrm{~m}$ & $9,5 \mathrm{~m}$ & 8,5 & $7,5 \mathrm{~m}$ & $9,5 \mathrm{~m}$ & $9,5 \mathrm{~m}$ & $9,5 \mathrm{~m}$ & $3 \mathrm{~m}$ & 9,5 & $9,5 \mathrm{~m}$ & YIII \\
\hline $8 \mathrm{~m}$ & $2 \mathrm{~m}$ & $\begin{array}{c}9,75 \\
\mathrm{~m}\end{array}$ & $\begin{array}{c}9,75 \\
\mathrm{~m}\end{array}$ & 8,75 & $7,75 \mathrm{~m}$ & $\begin{array}{c}9,75 \\
\mathrm{~m}\end{array}$ & $\begin{array}{c}9,75 \\
\mathrm{~m}\end{array}$ & $9,75 \mathrm{~m}$ & $3 \mathrm{~m}$ & 9,75 & $9,75 \mathrm{~m}$ & IX \\
\hline $8 \mathrm{~m}$ & $2 \mathrm{~m}$ & $10 \mathrm{~m}$ & $10 \mathrm{~m}$ & $9 \mathrm{~m}$ & $8 \mathrm{~m}$ & $10 \mathrm{~m}$ & $10 \mathrm{~m}$ & $10 \mathrm{~m}$ & $3 \mathrm{~m}$ & 10 & $10 \mathrm{~m}$ & $X$ \\
\hline
\end{tabular}

Цель исследования - практическое применение системы роста и развития тела человека.

Результаты исследования

В системе роста и развития тела человека 10 длин конституции тела: голова, шея, грудь, талия, таз , промежность, колено, икра, лодыжка, ступня. Каждый человек имеет свою формулу роста, есть промежуточные формулы, если учесть десятые, сотые доли значений.

Моя идея о наличии метки »m» на теле человека возникла в 7 лет. Для создания этой системы в течение всей жизни мной были проведены тысячи и тысячи обмеров. Это был тяжелый, но благодарный труд. Оказалось, что моя система приемлема для людей всех возрастов и имеет практическое применение.

Голова 8 »m»

Шея 2 «m»

Грудь 7,9»т»»

Талия 7,9«m»

Таз $8,4 \ll \mathrm{m} »$

Промежность 5 «m»

Колено 8,4«m»

Икра 8,4«m»

Лодыжка 8,4 «m»

Ступня 3 «m»

Фигура «Дева», возраст 40 лет, женская, «т»» = 2,5, О пястья $=22$, непропорциональная, рост 168
$168: 8=21: 2,5=8,4 » m »-$ индекс роста. $8 » \mathrm{~m} »$ $+2 » \mathrm{~m} »+5 » \mathrm{~m} »+3 » \mathrm{~m} »$ (4 стабильных параметра голова, шея, промежность, ступня) + 7,9»т» + 7,9»m» (2 нестабильных параметра - грудь, талия $)=$ $33,8 \mathrm{~m}+8,4$ » $\mathrm{\prime}$ *4 ( 4 нестабильных параметра - таз, колено, икра, лодыжка). В итоге: $8,4 » \mathrm{~m} » * 8=168$, индекс роста укладывается в фигуре 8 раз. Соблюдается канон Лисиппа. [1] Рост : $8=$ индекс роста : «m» = формула роста

От рождения и после рождения рост и развитие тела человека происходит согласно генетически заложенной в» т» программы роста и развития.

\section{Программы роста и развития}

1.Программа »Лилипут». Рост «m» и остановка роста «m» в 9 лет, на формуле роста $6,87 \mathrm{~m}$, остановка роста конституции тела в 9 лет.

2.Программа « Карлик». Рост «т»» и остановка роста «m» в 12,13 лет. Рост и развитие тела до I, II роста, до 25 лет.

3.Программа « Пигмей». Рост «m» и конституции тела идет параллельно. Остановка роста «m» в 12-13 лет. Остановка роста на I,II росте и до 25 лет.

4.Программа »Дуб». Рост «т»» до 13 лет, рост тела до 1 роста. До 25 лет. Рост «т» идет быстрее роста тела, «m»=3, но рост I.

5.Программа нормального роста и развития современного тела человека от I до Y роста. Рост 
«m» и остановка роста «т» в 12-13 лет. Рост и развитие тела до Ү роста, до 25 лет.

6.Программа «Тополь». Остановка роста «m" в 12-13 лет. Рост и развитие тела от YІ до IX роста, до 25 лет.

7.Программа «Былинка». Остановка роста «m» в 12-13 лет. Рост и развитие тела до Х роста, до 25 лет.

8.Программа »Великан». Остановка роста «m» в 15 лет. Рост и развитие тела до Х роста, до 25 лет.

9.Программа женской и мужской фигуры выражается в различии длины верхней и нижней частей туловища.

10. Программа «Пропорциональная фигура» определяет вертикальную разметку сетки поля по О ладони = индекс роста, О пястья * $2=20 » \mathrm{~m} »$

11. Программа «Непропорциональная фигура» определяет вертикальную разметку сетки поля по Опястья *2 не равно 20»m», Оладони не равно индексу роста.

І.Модульный расчет естественного размера одежды для форм тела человека (практическое применение системы)

Основные опорные участки тела человека, покрываемые одеждой - это голова, шея, плечи, грудь, живот, спина, ягодицы, предплечья, бедра, голени.

Характеристика фигур: рост [4], мерка модуля «m» (расстояние между складкой кожи на верхней ногтевой фаланге мизинца руки и верхушечной точкой кожи мизинца), мерка Опястья, (расстояние между основанием мизинца и основанием большого пальца руки при угле $45^{0}$ между ними), мерка Оладони (расстояние между основанием мизинца и основанием указательного пальцев руки*2), пропорциональность, ассиметрия туловища, посадка, осанка, обрисовка, направление боковой линии, индекс роста.

Индекс роста = Рост : 8 (канон Лисиппа) определяет горизонтальную разметку сетки поля. Оладони $=$ индекс роста, О пястья $* 2=20 » \mathrm{~m} »$ определяют пропорциональность фигуры.

Фигуры

Формула роста 7,52 8,25 7,9 8,5

Голова 8 «m» 8 «m» 8 «m» 8 «m»

Шея 2 «m» 2 «m» 2 «m» 2 «m»

Грудь $6,5 \ll \mathrm{m} » 7,5 \ll \mathrm{m} » 7,9 \ll \mathrm{m} » 8 \ll \mathrm{m} »$

Талия 6,5»m»7,5 «m» 7,9 «m» 8 «m» Таз 7 «m» $8,25\langle\mathrm{~m} » 6,6\langle\mathrm{~m} » 8,5 » \mathrm{~m} »$

Промежность 5 «m» 5 «m» 5 «m» 5 «m» Колено $7,5 » \mathrm{~m} » 8,25 \ll \mathrm{m} » 7,7 \ll \mathrm{m} » 8,5 » \mathrm{~m} »$

Икра 7,5»m» 8,25«m» 7,7 «m» 8,5»m» Лодыжка $8\langle\mathrm{~m} » 8,25\langle\mathrm{~m} » 7,7\langle\mathrm{~m} » 8,5 » \mathrm{~m} »$

Ступня 3 «m» 3 «m» 3 «m» 3 «m»

Пример№1. Фигура «Водолей», возраст 13 лет, женская, подросток, «т» $=2,3$, Опястья $=22$, непропорциональная, рост 139, формула роста = $139: 8: 2,3=7,52$, рост I. Размер одежды 44 Отложение жировой клетчатки и рост тканей для создания форм тела взрослого человека, полнота 0 , программа роста и развития $\mathrm{N}$.

Пример №2. Фигура «Козерог», возраст 61 год, женская, «m» $=2,5$, рост 165 , О пястья $=25$, пропорциональная, формула роста $165: 8$ :2,5= 8,25 , рост III, размер одежды 50, наслоения полноты нет, худобы нет, полнота IY, программа роста и развития тела $\mathrm{N}$

Пример №3. Фигура «Лев» Возраст 60 лет, мужская, «m» $=2,7$. Рост 172. О пястья $=25$, непропорциональная, формула роста $172: 8: 2,7=$ 7,9 , рост II, размер одежды 50, наслоения полноты нет, худобы нет, полнота 0, программа роста и развития $\mathrm{N}$.

Пример №4. Фигура «Весы». Возраст 16 лет, женская, «m» $=2,4$, рост 164, Опястья $=19$, непропорциональная. Формула роста 164:8 : 2,4 = 8,5 , рост IY, размер одежды 38 , что при ее модуле $\mathrm{m}=2,4$ означает худобу, можно ожидать наслоения полноты в детородном периоде до $4 \mathrm{~m}$, полнота 0 , программа роста и развития $\mathrm{N}$.

Визуальный осмотр фигур

Пример №5 фигура « Козерог» Возраст 76 лет, женская, мерная лента «m»: «m» $=2,5$, формула роста $164: 8: 2,5=8,25 \ll \mathrm{m} »$, рост III в системе роста и развития тела человека, О пястья $=25$, программа роста и развития $\mathrm{N}$, пропорциональная, рост (длина 164, масса 68 кг), О пястья *2=20»т» + «т» ( наслоение полноты). Размер одежды 20»m»+ «m». Припуск на утепляющую прокладку «т»

Фигура разномасштабная (длина грудной клетки меньше таковой в формуле роста на $\mathrm{m}$, длина таза больше таковой в формуле роста на $\mathrm{m}$ компенсация формулы роста). Лицо овальной формы, N. Шея наклонена вперед, угол наклона шеи от $18^{0}, \mathrm{~N}$.

Форма сечения основания шеи эллипс, сплюснутый со стороны спины, соответствует форме горловины спинки и переда, симметрия линии шеи $+0,4 »$ »» к полочке, глубина горловины спинки 1,4»m», полочки 2,5»m», ширина горловины спинки 3»m», полочки 3»m», высота плеча полочки 1,8»m», спинки 2,2»m», ширина плеча 5,3»m».

Наклон плеч $21^{0}, \mathrm{~N}$, осевая линия плеча относительно туловища отвесная, N. Тип осанки сутулый, длина рук больше обычной на «т», развитие мускулатуры слабое, ширина и длина спины до талии увеличены, а ширина и длина переда уменьшены. По степени развития мышц и подкожно - жирового слоя жилистые руки с равномерным распределением жира в плечевой части, узкие плечи, верхняя часть спины округлая, с выступающими лопатками, прогиб бокового контура туловища на уровне линии талии средний.

Величина Пк больше, чем у фигуры с нормальной осанкой. Осанка = Дтс (истинная) - Дтп $\mathrm{I}=16,8 » \mathrm{~m} »-16,4 » \mathrm{~m} »=0,4 » \mathrm{~m} »($ сутулость $)$.

Из-за увеличения ГтI на «m» увеличен живот на средней линии полочки на 3, «нижний», на 3»m» ниже горизонтальной разметки линии талии.

В прилегающем силуэте плечевой срез спинки со средним швом. Согласно Пк - Г т I / 2* 0,4 = 0 линия горловины в прилегающей одежде остается на месте, повышение горловины спинки на $0,25 \mathrm{~m}$.

Форма грудной клетки широкая, развернутая. Грудь плоская, степень развития грудных желез 
2»m», выступающие точки грудных желез смещены вниз и незначительно выступают вперед относительно выступа живота, живот расположен несколько ниже и больше выдается вперед. Ассиметрия туловища.

Разница в измерениях обхватов правой и левой половинки по линии талии $0,4 » \mathrm{~m} »$, по линии таза $0,8 » \mathrm{~m} »$, форма бедер $\mathrm{N}$, выступ ягодиц уменьшен, низкое расположение ягодиц.

Положение осей бедра и голени, степень развития мышц и подкожно-жирового слоя ног нормальное. Носки ног и пятки расположены на одной линии. Боковой шов проходит через П5, Пв [9]. Отклонение средней линии полочки и спинки на 3»m» от вертикали на линии ступни. Форма ног на линии колена требует увеличения ширины среднего шва задней половинки брюк на 1,5»m», наибольшее наслоение полноты «т», предельная худоба « $2 \mathrm{~m} »$.

Если повернуть горизонтальную ось прямой классической юбки на линии талии середины спинки на «т», смещая линию талии середины спинки на 2»m», оформить вытачки, можно получить прямую юбку без боковой линии, со сгибом середины переда, со смещенной осью линии талии для фигуры «Козерог». Форма ног этой фигуры требует на линии колена увеличения ширины среднего шва задней половинки брюк на $1,5 \ll \mathrm{m} »$.

Обрисовка фигур, спереди, сзади, сбоку, в профиль. Видны гармония во всех частях тела или отклонения фигур от нормы.

Вход в систему. Посадка спинки и полочки от линии плеча зависит от посадки шеи на плечевом поясе. При посадке $\mathrm{N}$ сутулость 1 увеличивает «m» спинки на 1. В результате глубина горловины спинки $=\langle\mathrm{m} »+1$. Высота плеча строится от понижения линии плеча вперед из-за сутулости на 1. В результате Гл горл полочки $=3 » \mathrm{~m} »-1$, Шгорл $=3 » \mathrm{~m}$. При накладке муляжного воротника, если нужно, расставляют плечо, но середина спинки и полочки на входе должны совпадать с точками на теле.

Формула вертикальной разметки сетки поля для естественного размера одежды фигуры (Е), фигура женская спинка пройма полочка

Уровень проймы $8 » \mathrm{~m} »+4 » \mathrm{~m} »+8 » \mathrm{~m} »=20$ $\ll \mathrm{m} »=\mathrm{CrIII}$

Уровень талии $\mathrm{C}_{\mathrm{T}}=20 » \mathrm{~m} »-3 » \mathrm{~m} »=17 » \mathrm{~m} »$

Уровень таза Стаза $=20 » \mathrm{~m} »+3 » \mathrm{~m} »=23 » \mathrm{~m} »$

Уровень рукава Оп + ПСrIII

Пример№6 Грудь имеет впалую форму, сутулость «т»»

полочка $=8 \mathrm{~m}-\mathrm{m}=7 \mathrm{~m}$, спинка $=8 \mathrm{~m}+\mathrm{m}=9 \mathrm{~m}$

Итого $9 \mathrm{~m}+4 \mathrm{~m}+7 \mathrm{~m}=20 » \mathrm{~m} »$

Таблица 2.

Естественный размер одежды для фигур

\begin{tabular}{|c|c|c|c|c|c|c|c|c|c|c|c|c|c|c|c|c|c|c|c|c|}
\hline «m» & 1, & 1, & 1, & 1, & 1, & 1, & 1, & 1, & 1, & 2, & 2, & 2, & 2, & 2, & 2, & 2, & 2, & 2, & 2, & 3, \\
\hline $\begin{array}{c}\text { разме } \\
\text { p } \\
\text { одежд } \\
\text { ы }\end{array}$ & 22 & 24 & 26 & 28 & 30 & 32 & 34 & 36 & 38 & 40 & 42 & 44 & 46 & 48 & 50 & 52 & 54 & 56 & 58 & 60 \\
\hline
\end{tabular}

Формула $20 » \mathrm{~m} » 20 * 1,1=$ размер одежды $=$ $\mathrm{CrIII}=22$ и т. д.

Полнота женщины - разность между CrIII и Стаза. Полнота мужчины - разность между CrIII и Ст. Это влияет на отклонение средней линии спинки и средней линии полочки от вертикали до ступни.
При наслоении полноты (распределение по телу жировой клетчатки без роста тканей) естественный размер одежды увеличивается на величину «m» и т. д. CrIII $=20 »$ m» не соответствует О пястья *2. При наслоении полноты на «т»» и т. д., расчет формулы оболочки тела идет по новому $\mathrm{CrIII}=20 » \mathrm{~m} »+» \mathrm{~m} »$ и т.д. 
Таблица 4.

Модульный расчет естественного размера одежды для форм тела человека

\begin{tabular}{|c|c|c|c|}
\hline № & Горизонтальная разметка сетки поля & $\begin{array}{c}\text { Вертикальная разметка сетки поля, } \\
\text { уровень проймы }\end{array}$ & Силуэт \\
\hline 1 & грудь + талия + таз & $\begin{array}{c}\text { спинка + пройма + полочка } \\
8 \mathrm{~m}+4 \mathrm{~m}+8 \mathrm{~m}\end{array}$ & Оболочка тела \\
\hline 2 & грудь + талия+ таз & $\begin{array}{c}8 m+4 m+8 m \\
+0,5 m \\
8 m+4,5 m+8 m\end{array}$ & плотно- прилегающий \\
\hline 3 & грудь + талия + таз & $\begin{array}{c}8 m+4 m+8 m \\
+m \\
8 m+5 m+8 m \\
\end{array}$ & прилегающий \\
\hline 4 & грудь + талия + таз & $\begin{array}{c}8 m+4 m+8 m \\
-0,5 m+m-0,5 m \\
m(\Pi C r I I I=m) \\
7,5 m+6 m+7,5 m\end{array}$ & прилегающий \\
\hline 5 & грудь +талия + таз & $\begin{array}{c}8 m+4 m+8 m \\
+m \\
8 m+5 m+8 m \\
\end{array}$ & прилегающий \\
\hline 6 & грудь + талия + таз & $\begin{array}{c}8 m+4 m+8 m \\
0,1 m+m+0,4 m \\
8,1 m+5 m+8,4 m\end{array}$ & полуприлегающий \\
\hline 7 & грудь + талия + таз & $\begin{array}{c}8 m+4 m+8 m \\
0,1 m+m+0,9 m \\
8,1 m+5 m+8,9 m \\
\end{array}$ & прямой, трапеция \\
\hline 8 & грудь + талия+ таз & $\begin{array}{c}\text { Ш изд = CrIII + 3m } \\
\text { Вок }=\text { Шрук }=10 » \text { »» } \\
\text { проймы нет }\end{array}$ & туника \\
\hline 9 & грудь + талия + таз & $\begin{array}{c}8 m+4 m+8 m \\
0,1 m+m+0,9 m \\
8,1 m+5 m+8,9 m \\
\end{array}$ & свободный \\
\hline 10 & грудь + талия+ таз & $\begin{array}{c}8 m+4 m+8 m \\
0,1 m+1,6 m+0,6 m \\
8,1 m+5,6 m+8,6 m\end{array}$ & прилегающий \\
\hline 11 & грудь +талия + таз & $\begin{array}{c}8 \mathrm{~m}+4 \mathrm{~m}+8 \mathrm{~m} \\
0,1 \mathrm{~m}+1,8 \mathrm{~m}+0,6 \mathrm{~m} \\
+1,4 \mathrm{~m} \text { отвед. бочка } \\
8,1 \mathrm{~m}+7,2 \mathrm{~m}+8,6 \mathrm{~m} \\
\end{array}$ & полуприлегающий \\
\hline 12 & грудь + талия + таз & $\begin{array}{c}8 m+4 m+8 m \\
0,2 m+2 m+0,8 m \\
8,2 m+6 m+8,8 m \\
\end{array}$ & свободный \\
\hline 13 & грудь + талия + таз & $\begin{array}{c}8 m+4 m+8 m \\
0,4 m+2,4 m+0,8 m \\
8,4 m+6,4 m+8,8 m\end{array}$ & свободный \\
\hline 14 & грудь +талия +таз + ступня & полнота I-Y + 0,5 m & плотно- прилегающий \\
\hline 15 & грудь +талия + таз + ступня & полнота I - Y + m & прилегающий \\
\hline
\end{tabular}


Конструкция. «Юбка, юбка-брюки, брюки без боковых швов, гамаши, трусы, плавки» $\mathrm{\Pi CrII=0;} \mathrm{ПСтаза}=0$

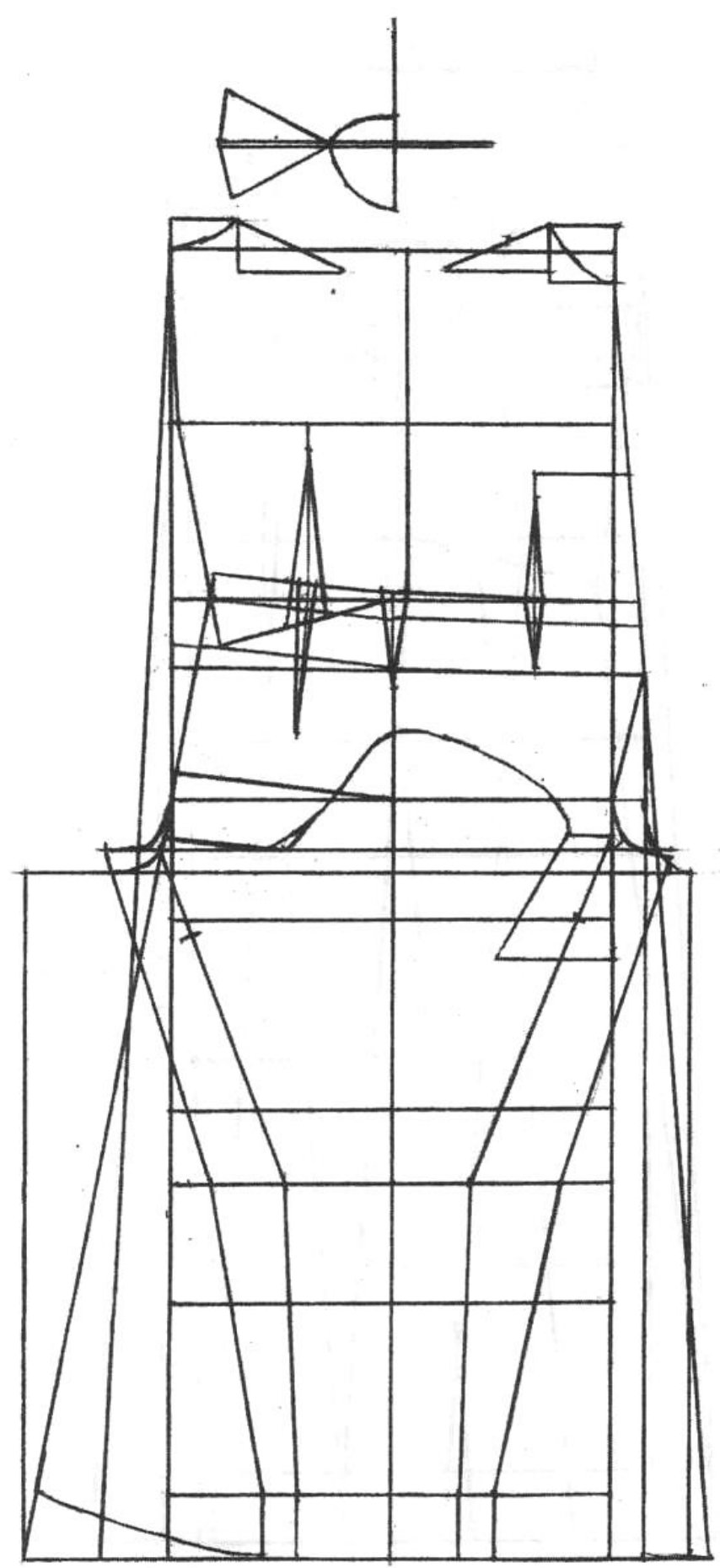


Таблица3.

Определение симметричности фигур

\begin{tabular}{|c|c|c|c|}
\hline Спинка & Пройма & Полочка & Степень симметрии \\
\hline $8 \mathrm{~m}$ & $4 \mathrm{~m}$ & $8 \mathrm{~m}$ & равновесие \\
\hline $7,5 \mathrm{~m}$ & $4 \mathrm{~m}$ & $8,5 \mathrm{~m}$ & $\mathrm{~N}$ \\
\hline $8,5 \mathrm{~m}$ & $4 \mathrm{~m}$ & $7,5 \mathrm{~m}$ & $\mathrm{~N}$ \\
\hline $7 \mathrm{~m}$ & $4 \mathrm{~m}$ & $9 \mathrm{~m}$ & перегиб \\
\hline $9 \mathrm{~m}$ & $4 \mathrm{~m}$ & $7 \mathrm{~m}$ & сутулость \\
\hline $10 \mathrm{~m}$ & $5 \mathrm{~m}$ & $9 \mathrm{~m}$ & $\mathrm{~N}$ \\
\hline $9 \mathrm{~m}$ & $5 \mathrm{~m}$ & $10 \mathrm{~m}$ & $\mathrm{~N}$ \\
\hline $9,5 \mathrm{~m}$ & $5 \mathrm{~m}$ & $9,5 \mathrm{~m}$ & равновесие \\
\hline $8,5 \mathrm{~m}$ & $7,5 \mathrm{~m}$ & $10 m+5 m$ & перегиб 5m (голуб. грудь) \\
\hline $9 \mathrm{~m}$ & $7,25 \mathrm{~m}$ & $10 m+4,5 m$ & перегиб 4,5m \\
\hline $9 m$ & $7 \mathrm{~m}$ & $10 m+4 m$ & перегиб 4m \\
\hline $9 \mathrm{~m}$ & $6,75 \mathrm{~m}$ & $10 m+3,5 m$ & перегиб 3,5m \\
\hline $9 \mathrm{~m}$ & $6,5 \mathrm{~m}$ & $10 m+3 m$ & перегиб 3m \\
\hline $9 \mathrm{~m}$ & $6,25 \mathrm{~m}$ & $10 \mathrm{~m}+2,5 \mathrm{~m}$ & перегиб 2,5m \\
\hline $9 \mathrm{~m}$ & $6 \mathrm{~m}$ & $10 m+2 m$ & перегиб 2m \\
\hline $9 \mathrm{~m}$ & $5,75 \mathrm{~m}$ & $10 \mathrm{~m}+1,5 \mathrm{~m}$ & перегиб 1,5m \\
\hline $9 \mathrm{~m}$ & $5,5 \mathrm{~m}$ & $10 \mathrm{~m}+\mathrm{m}$ & перегиб m \\
\hline $9 \mathrm{~m}$ & $5 \mathrm{~m}$ & $10 m+0,5 m$ & перегиб 0,5m \\
\hline $10 \mathrm{~m}+0,5 \mathrm{~m}$ & $5 \mathrm{~m}$ & $9 \mathrm{~m}$ & сутулость $0,5 \mathrm{~m}$ \\
\hline $10 m+m$ & $5,5 \mathrm{~m}$ & $9 \mathrm{~m}$ & сутулость m \\
\hline $10 \mathrm{~m}+1,5 \mathrm{~m}$ & $5,75 \mathrm{~m}$ & $9 \mathrm{~m}$ & сутулость $1,5 \mathrm{~m}$ \\
\hline $10 m+2 m$ & $6 \mathrm{~m}$ & $9 \mathrm{~m}$ & сутулость $2 \mathrm{~m}$ \\
\hline $10 \mathrm{~m}+2,5 \mathrm{~m}$ & $6,25 \mathrm{~m}$ & $9 \mathrm{~m}$ & сутулость $2,5 \mathrm{~m}$ \\
\hline $10 m+3 m$ & $6,5 \mathrm{~m}$ & $9 \mathrm{~m}$ & сутулость $3 \mathrm{~m}$ \\
\hline $10 \mathrm{~m}+3,5 \mathrm{~m}$ & $6,75 \mathrm{~m}$ & $9 \mathrm{~m}$ & сутулость $3,5 \mathrm{~m}$ \\
\hline $10 m+4 m$ & $7 \mathrm{~m}$ & $9 \mathrm{~m}$ & сутулость $4 \mathrm{~m}$ \\
\hline $10 m+4,5 m$ & $7,25 \mathrm{~m}$ & $9 \mathrm{~m}$ & сутулость $4,5 \mathrm{~m}$ \\
\hline $10 m+5 m$ & $7,5 \mathrm{~m}$ & $8,5 \mathrm{~m}$ & сутулость 5m (горб) \\
\hline $9 m+m$ & $6,5 m+0,5$ & $10 m+3 m$ & смешанный тип $3 \mathrm{~m}$ \\
\hline $9 m+0,5 m$ & $6 \mathrm{~m}$ & $10 m+2 m$ & смешанный тип $2 \mathrm{~m}$ \\
\hline
\end{tabular}

Заключение. На основе системы роста и развития тела человека, мерки роста, мерки модуля »m» сначала определяют естественный размер одежды, затем учитывают наслоение полноты, худобы данной фигуры.

II. Фактор запуска естественных родов (практическое применение системы)

Актуальной проблемой акушерства и гинекологии в настоящее время является вопрос: «Что является сигналом для запуска естественных родов?», так как внутриутробное состояние ребенка рассматривается как основной фактор риска заболеваний взрослого организма.

Эволюционно подготовленный биологический процесс изгнания из матки плода после достижения плодом жизнеспособности, а также плаценты с оболочками и околоплодными водами, возникает при сроке беременности от 37 недель до 41 недели 6 дней от первого дня последней менструации. [10]

По данным современной литературы эпифиз плода выделяет «плодовый фактор», который развязывает родовую деятельность и воздействует на корковое вещество надпочечников плода, стимулируя синтез кортизола, который проникает в околоплодные воды и достигает зоны непосредственного контакта плодовых и материнских тканей. [9]
Одновременно прекращается в эпифизе синтез мелатонина, блокирующего гипоталамус плода, происходит разрушение лизосом, выброс главных модуляторов сократительной активности матки плодовых простагландинов Е2 из водных оболочек и материнских F2 из миометрия. которые развязывают автоматическую кодовую родовую деятельность, выброс материнского гормона окситоцина, который отвечает за начало родовой деятельности, гормона эндорфина (нейрогормон с морфоподобными функциями) - природного обезболивающего средства.[8]

Своевременные самопроизвольные роды через естественные родовые пути представляют собой асептическую воспалительную реакцию (инфильтрация зрелой шейки матки лейкоцитами) и реакцию отторжения в развитии родов, а также ведут подготовку иммунной системы плода к его внеутробному существованию. [10]

Что является сигналом к началу естественных родов? Почему прекращается синтез мелатонина в эпифизе плода и происходит выброс простагландинов плодового и материнского происхождения, выброс материнских гормонов окситоцина, эндорфина?

Вид Homo sapiens запрограммирован на генетически закрепленный срок внутриутробного 
развития, где различают два периода: эмбриональный - до 2 месяцев, фетальный - с 3 месяцев и до самых родов. [8]

\section{Результаты исследований}

Рассмотрим систему роста и развития тела человека на отрезке - закладка модуля «т» до периода «Новорожденный».

Рост ребенка, формирование его органов и систем идет закономерно в различные периоды внутриутробного развития, что подчинено генетическому коду, заложенному в оплодотворенной яйцеклетке и закрепленному в процессе эволюции человека.

Индекс роста $=\langle\mathrm{m} », 2\langle\mathrm{~m} », 2,8\langle\mathrm{~m} », 3,4 » \mathrm{~m} »$, $3,9 » \mathrm{~m} », 3,95 » \mathrm{~m} », 5 » \mathrm{~m} », 5\langle\mathrm{~m} »$.

Формула роста $=$ индекс роста : «т»».

$1,2,2,8,3,4,3.9,3,95,5,5,55$ формула роста плода

234567891011 месяцы беременности

Начало закладки модуля «т»» происходит на 2м месяце беременности. Все месяцы роста и развития тела человека до рождения отслежены и выполнены экспериментальным путем.

1-й месяц. Эмбрион разделен на две симметричные половины. Между зачатками пальцев рук и ног верхних и нижних конечностей кожная перепонка. 8 длин роста. Рост 6 мм. Индекс роста $=6: 8=0,75 \mathrm{Mм}$

2- й месяц. Между пальцами отсутствует кожная перепонка. Появляются ногти. Идет закладка модуля «т». Перераспределение на 10 длин роста, рост 3,5 см. Индекс роста $=3,5: 8=$ $0,43 \mathrm{~cm}$. При $\mathrm{m}=0,43 \mathrm{~cm}$ формула роста $=0,43: 0,43$ $=1$

3-й месяц. У плода длинные руки и короткие ноги, ладонь с фалангами пальцев без кожной перепонки. Есть пальчики на руках и ногах. Рост 7см. Индекс роста $=7: 8=0,87$. При $\mathrm{m}=0,43 \mathrm{~cm}$ формула роста $=0,87: 0,43=2$

4-й месяц. Сформированы пальцы рук, ног, на них появляется индивидуальный рисунок. Сформированы ногти, они покрывают только край ногтевой фаланги. Видны крохотные ладони рук. О пястья руки $=6,2$ см. Рост 14,8. Индекс роста = 14,8: $8=1,85$ При «m» $=0,62 \mathrm{~cm}$ формула роста $=1,85$ : $0,62=2,8$

5-й месяц. Различимы фаланги пальцев. Конечности сформированы. Рост 23см. Индекс роста $=23: 8=2,87$ При «m» $=0,84 \mathrm{~cm}$ формула роста $2,87: 0,84=3,4$

6-й месяц. Плод является жизнеспособным. Ногти не доходят до края ногтевой фаланги. Рост 27. Индекс роста 27: $8=3,5$ При «т»» $=0,9 \mathrm{~cm}$ формула роста $=3,5: 0,9=3,87$

7-й месяц. Ногти не доходят до края ногтевой фаланги. Рост 31,6. Индекс роста $=31,6: 8=3,9$. При «m»=1см формула роста $=3,9: 1=3,9$

8-й месяц. Развитие плода не закончилось. Рост 40. Индекс роста $=40: 8=5$ При $\mathrm{m}=1$ формула роста $=5: 1=5$

9-й месяц. Все органы и системы полностью развиты для роста и развития ребенка вне утробы матери. Ногти достигают кончиков ногтевых фаланг. Формула роста $=5$, рост модуля «т» - 1,1 $1,2,1,3$

10 месяц. Все органы и системы полностью развиты для роста и развития ребенка вне утробы матери. Ногти достигают кончиков ногтевых фаланг. Формула роста 5 , рост модуля «т» - 1,1 , $1,2,1,3$, увеличение веса плода.

11 месяц. А.Пролонгированная поздняя своевременная беременность, которая длится от $41+0$ недели до 41 недели 6 дней и является вариантом доношенной беременности. Параметры сходны с 10 месяцем роста и развития плода. Увеличение веса плода.

Б.Переношенная беременность (наличие синдрома Беллентайна Рунге: повышение плотности костей черепа, отсутствие сыровидной смазки, мацерированная кожа, "банные" ладони и стопы, длинные ногти) встречается при стрессе, некоторых видах экстрагенитальной патологии (заболевания ЛОР-органов, мочевыделительной системы и органов зрения) и наличии мужского пола плода, при рождении родителей от запоздалых родов, перенашивания беременности в анамнезе, при неготовности родовых путей к родам у первородящих женщин в сроке 284 дня и более. Параметры сходны с 10 месяцем роста и развития плода. Увеличение веса. плода. [10]

Нормальная программа роста и развития тела человека до рождения

Рост 44cм :8 = 5,5 - индекс роста. При «т»»= $1,15,5: 1,1=5$ формула роста

Рост $48 \mathrm{~cm}: 8=6-$ индекс роста. При «т»» $=1,2$ $6: 1,2=5$ формула роста

Рост 52см : $8=6,5$ - индекс роста. При «т»»= $1,36,5: 1,3=5$ формула роста

Формула роста $=5$, но значения роста разные из - за разного модуля.

Происходит запуск естественных родов через систему эпифиз - гипоталамус - гипофиз надпочечники плода, в зависимости от значения «m». Атавизм:

Рост 56см : $8=7$ - индекс роста. При «m» $=1,4$ $7: 1,4=5$ формула роста

Рост 60см : $8=7,5$ - индекс роста. При «т»»= $1,57,5: 1,5=5$ формула роста

Рост $64 \mathrm{~cm}: 8=8$ - индекс роста. При «т» $=1,6$ $8: 1,6=5$ формула роста

Рост 68см : $8=8,5$ - индекс роста При «т»»= $1,78,5: 1,7=5$ формула роста

Рост 72см : $8=9$ - индекс роста. При «т»» $=1,8$ $9: 1,8=5$ формула роста

Атавизм говорит о существовании в далекие времена на планете «Земля» людей - великанов, рост которых при рождении составлял от 56 до $72 \mathrm{~cm}$. В настоящее время таз современной женщины приспособлен для рождения людей с ростом от 44 до $52 \mathrm{~cm}$.

\section{Заключение.}

Фактор запуска естественных родов заложен в модуле «m». Сигнал к запуску естественных родов в организме женщины дает созревший плод при значении модуля на теле плода $1,1,1,2,1,3$ через систему эпифиз - гипоталамус - гипофиз - 
надпочечники плода. Эпифиз контролирует соматическую зрелость плода с помощью генетически запрограммированного модуля «т». Включаются регуляторные механизмы снятия защитных барьеров во время беременности и гипоталамус начинает контролировать эндогенный водитель ритма организма от внутриутробного периода до конца жизни.

Таблица 2.

Параметры фигуры тела человека в разные возрастные периоды.

\begin{tabular}{|c|c|c|c|c|c|c|c|c|c|}
\hline Беременность & $\begin{array}{c}\text { Возрас } \\
\text { т } \\
\text { период } \\
\text { ы }\end{array}$ & «m» & рост & $\begin{array}{c}\text { Обхва } \\
\text { т } \\
\text { пясть } \\
\text { я }\end{array}$ & $\begin{array}{l}\text { Индек } \\
\text { с } \\
\text { роста }\end{array}$ & $\begin{array}{l}\text { Форму } \\
\text { ла } \\
\text { роста }\end{array}$ & $\mathrm{Bec}$ & $\begin{array}{c}\text { Особенности } \\
\text { возрастных } \\
\text { периодов }\end{array}$ & $\begin{array}{l}\text { Разме } \\
\mathrm{p} \\
\text { одежд } \\
\text { Ы }\end{array}$ \\
\hline & 1 месяц & & 6мм & & $\begin{array}{c}0,75 \mathrm{M} \\
\mathrm{M}\end{array}$ & & & $\begin{array}{c}\text { Головастик с } \\
\text { жабрами } \\
\end{array}$ & \\
\hline & 2 месяц & $\begin{array}{c}0,43 \mathrm{c} \\
\mathrm{M}\end{array}$ & $3,5 \mathrm{~cm}$ & $4 \mathrm{~cm}$ & $0,43 \mathrm{~cm}$ & 1 & & $\begin{array}{c}\text { Первые нервные } \\
\text { узлы, закладка } \\
\text { модуля }\end{array}$ & \\
\hline & 3 месяц & $\begin{array}{c}0,43 \mathrm{c} \\
\mathrm{M}\end{array}$ & $7 \mathrm{~cm}$ & $4 \mathrm{~cm}$ & $0,87 \mathrm{~cm}$ & 2 & & $\begin{array}{c}\text { Головастик, } \\
\text { развиты глаза }\end{array}$ & \\
\hline & 4 месяц & $\begin{array}{c}0,62 \mathrm{c} \\
\mathrm{M}\end{array}$ & $15 \mathrm{~cm}$ & $6 \mathrm{~cm}$ & $1,8 \mathrm{~cm}$ & 2,8 & & $\begin{array}{c}\text { Впервые стук } \\
\text { сердца }\end{array}$ & \\
\hline & 5 месяц & $\begin{array}{c}0,84 \mathrm{c} \\
\mathrm{M}\end{array}$ & $23 \mathrm{~cm}$ & 8,4 & $2,87 \mathrm{~cm}$ & 3,4 & & $\begin{array}{c}\text { Намечаются } \\
\text { половые органы }\end{array}$ & \\
\hline & 6 месяц & $0,9 \mathrm{~cm}$ & $28 \mathrm{~cm}$ & $9 \mathrm{~cm}$ & $3,5 \mathrm{~cm}$ & 3,9 & & $\begin{array}{c}\text { Плод готов к } \\
\text { рождению, } \\
\text { набор веса }\end{array}$ & \\
\hline & 7 месяц & $1 \mathrm{~cm}$ & $31,6 \mathrm{~cm}$ & $10 \mathrm{~cm}$ & $3,95 \mathrm{~cm}$ & 3,95 & & $\begin{array}{c}\text { Открываются } \\
\text { глаза }\end{array}$ & \\
\hline & 8 месяц & $1 \mathrm{~cm}$ & $40 \mathrm{~cm}$ & $10 \mathrm{~cm}$ & $5 \mathrm{~cm}$ & 5 & & $\begin{array}{c}\text { Плод готов к } \\
\text { рождению, } \\
\text { развитие не } \\
\text { закончилось } \\
\end{array}$ & \\
\hline & $\begin{array}{c}9,5- \\
10.5 \\
\text { месяце } \\
\text { в } \\
38-42 \\
\text { недель }\end{array}$ & $\begin{array}{l}1,1 \\
1,2, \\
1,3 \\
\mathrm{~cm}\end{array}$ & $\begin{array}{c}44 \\
48 \\
52 \mathrm{~cm}\end{array}$ & $\begin{array}{c}10 \\
11 \\
12 \mathrm{~cm}\end{array}$ & $\begin{array}{c}5,5 \\
6 \\
6,5\end{array}$ & $\begin{array}{l}5 \\
5 \\
5\end{array}$ & $\begin{array}{l}3,2 \\
3,4 \\
3,6\end{array}$ & $\begin{array}{c}\text { Перераспределе } \\
\text { ние ростов } \\
\text { согласно } \\
\text { значениям «т» } \\
\text { Запуск } \\
\text { естественных } \\
\text { родов } \\
\end{array}$ & \\
\hline $\begin{array}{c}\text { Новорожденн } \\
\text { ый }\end{array}$ & $\begin{array}{l}1-40 \\
\text { дней }\end{array}$ & $1,2 \mathrm{~cm}$ & $48 \mathrm{~cm}$ & $11 \mathrm{~cm}$ & $6 \mathrm{~cm}$ & 5 & $\begin{array}{l}3,4 \\
\text { кг }\end{array}$ & & 24 \\
\hline $\begin{array}{l}\text { Грудной } \\
\text { возраст }\end{array}$ & $\begin{array}{c}40 \\
\text { дней-1 } \\
\text { год }\end{array}$ & $1,3 \mathrm{~cm}$ & $56 \mathrm{~cm}$ & $15 \mathrm{~cm}$ & $8 \mathrm{~cm}$ & 5,37 & $\begin{array}{c}6,37 \\
\text { кг }\end{array}$ & $\begin{array}{c}\text { Длина головы }= \\
1 / 4 \text { роста }\end{array}$ & 26 \\
\hline $\begin{array}{l}\text { Раннее } \\
\text { детство }\end{array}$ & $\begin{array}{c}1-3 \\
\text { года } \\
\end{array}$ & $1,5 \mathrm{~cm}$ & $69,6 \mathrm{~cm}$ & $16 \mathrm{~cm}$ & $9,3 \mathrm{~cm}$ & 5,75 & $\begin{array}{c}9,11 \kappa \\
\Gamma\end{array}$ & $\begin{array}{c}\text { Длина головы } \\
1 / 4,5 \text { роста }\end{array}$ & 30 \\
\hline $\begin{array}{c}\text { I период } \\
\text { детства }\end{array}$ & 3-7 лет & $1,9 \mathrm{~cm}$ & $\begin{array}{c}108,8 \mathrm{c} \\
\mathrm{M}\end{array}$ & $20 \mathrm{~cm}$ & $13 \mathrm{~cm}$ & 6,5 & $\begin{array}{c}14,6 \kappa \\
\Gamma\end{array}$ & $\begin{array}{c}\text { Длина головы } \\
1 / 5,5 \text { роста }\end{array}$ & 32 \\
\hline $\begin{array}{c}\text { II период } \\
\text { детства }\end{array}$ & $\begin{array}{c}7-12 \\
\text { лет }\end{array}$ & $2,5 \mathrm{~cm}$ & $\begin{array}{c}141,6 \mathrm{c} \\
\mathrm{M}\end{array}$ & $21 \mathrm{~cm}$ & $15,5 \mathrm{~cm}$ & 7,62 & 28 кг & $\begin{array}{c}\text { Длина головы } \\
1 / 6 \text { роста } \\
\end{array}$ & 40 \\
\hline Подростковый & $\begin{array}{c}12-16 \\
\text { лет }\end{array}$ & $2,5 \mathrm{~cm}$ & $162 \mathrm{~cm}$ & $25 \mathrm{~cm}$ & $20,2 \mathrm{~cm}$ & 7,9 & 43кг & $\begin{array}{c}\text { Длина головы } \\
1 / 7,5 \text { роста } \\
\end{array}$ & 42 \\
\hline Юношеский & $\begin{array}{c}16,21 \\
\text { год }\end{array}$ & $2,5 \mathrm{~cm}$ & $170 \mathrm{~cm}$ & $25 \mathrm{~cm}$ & $\begin{array}{c}21,25 \mathrm{c} \\
\mathrm{M}\end{array}$ & 8,5 & 63 кг & $\begin{array}{c}\text { Длина головы }= \\
1 / 8 \text { роста } \\
\end{array}$ & 50 \\
\hline $\begin{array}{c}\text { I период } \\
\text { зрелого } \\
\text { возраста } \\
\end{array}$ & $\begin{array}{l}21-35 \\
\text { лет }\end{array}$ & $2,5 \mathrm{~cm}$ & $170 \mathrm{~cm}$ & $25 \mathrm{~cm}$ & $\begin{array}{c}21,25 \mathrm{c} \\
\mathrm{M}\end{array}$ & 8,5 & 70кг & $\begin{array}{c}\text { Воспроизводств } \\
\text { о потомства }\end{array}$ & 50 \\
\hline $\begin{array}{l}\text { II период } \\
\text { зрелого } \\
\text { возраста }\end{array}$ & $\begin{array}{l}35-60 \\
\text { лет }\end{array}$ & $2,5 \mathrm{~cm}$ & $165 \mathrm{~cm}$ & $25 \mathrm{~cm}$ & $\begin{array}{c}20,625 \\
\text { cM }\end{array}$ & 8,25 & 70кг & $\begin{array}{l}\text { Ассиметрия } \\
\text { туловища, } \\
\text { уменьшение } \\
\text { длины тела }\end{array}$ & 50 \\
\hline Пожилой & $\begin{array}{c}60- \\
75 \text { лет }\end{array}$ & $2,5 \mathrm{~cm}$ & $\begin{array}{c}162,5 \mathrm{c} \\
\mathrm{M}\end{array}$ & $25 \mathrm{~cm}$ & $\begin{array}{c}20,625 \\
\mathrm{~cm}\end{array}$ & 8,25 & 70кг & $\begin{array}{l}\text { Уменьшение } \\
\text { длины тела, }\end{array}$ & 52 \\
\hline
\end{tabular}




\begin{tabular}{|c|c|c|c|c|c|c|c|c|c|}
\hline & & & & & & & $\begin{array}{c}\text { наслоение } \\
\text { полноты }\end{array}$ & \\
\hline Старческий & $\begin{array}{c}75-90 \\
\text { лет }\end{array}$ & $2,5 \mathrm{~cm}$ & $\begin{array}{c}162,5 \mathrm{c} \\
\text { м }\end{array}$ & $25 \mathrm{~cm}$ & $\begin{array}{c}20,625 \\
\mathrm{~cm}\end{array}$ & 8,25 & 70 кг & $\begin{array}{c}\text { Наслоение } \\
\text { полноты }\end{array}$ & $52-50$ \\
\hline долгожители & $\begin{array}{c}90 \text { лет } \\
\text { и } \\
\text { старше }\end{array}$ & $2,5 \mathrm{~cm}$ & $160 \mathrm{~cm}$ & $25 \mathrm{~cm}$ & $20 \mathrm{~cm}$ & 8 & 65 кг & $\begin{array}{c}\text { Уменьшение } \\
\text { длины и веса } \\
\text { тела }\end{array}$ & $50-48$ \\
\hline
\end{tabular}

\section{Библиографический список}

1. Вальдгауэр О.Ф. Лисипп. Берлин,1923,17с

2. Красникова - Аксенова Л.Я. « Самоучитель по конструированию и моделированию одежды», Москва 1991г, фирма « Любакс», 65с.

3. Красникова - Аксенова Л.Я. «Крой без тайн», 2007 г. - М. НОУ, Любакс», 302 с., 1075ил

4. РоссолимоТ. Рост и развитие человеческого организма : 1962г.

5.Схема возрастной периодизации онтогенеза человека, принятая на VII Всесоюзной конференции по проблемам возрастной морфологии, физиологии и биохимии АПН СССР (Москва, 1965)

6. Стандартинформ. Типовые фигуры мальчиков. Размерные признаки. 2006. 100 с.

7. Стандартинформ. г.. Москва Типовые фигуры мужчин. Размерные признаки. 2005. 27 с.

8. Старцева Н. Материнство под угрозой, или Агрессивный акушерский вандализм [Электронный ресурс] // Материалы IV Международного конгресса «Молодое поколение XXI века: актуальные проблемы социальнопсихологического здоровья», 22- 24 сентября 2009 года, г. Киров. URL: http://www.medicusamicus.com/index.php?action $=4 \mathrm{x}$ 2171x1 (дата обращения: ( 01.013. 2020).

9. Савельева Г.М. Ведение физиологических и осложненных родов. Акушерство и гинекология. 2011. - № 3. - С. 4-10.

10. Тысячный О.В. ОПТИМИЗАЦИЯ ТАКТИКИ ВЕДЕНИЯ БЕРЕМЕННОСТИ, РОДОВ И ПЕРИНАТАЛЬНЫЕ ИСХОДЫ ПРИ ПЕРЕНОШЕННОЙ БЕРЕМЕННОСТИ. Диссертация на соискание ученой степени кандидата медицинских наук. Москва - 2017

11.Шершнева Л.П. Пирязева Т.В. Ларькина Л.В. Основы морфологии и биомеханики человека М. 2010 г.

12.ЦНИИШП г. Москва Типовые фигуры девочек. Размерные признаки. 2004. 98 с.

13.ЦНИИШП. Москва Типовые фигуры женщин. Размерные признаки. Москва. 2003.107 с

\section{Bibliographic list}

1. Waldhauer O.F. Lysippus. Berlin, 1923.17s

2. Krasnikova - Aksenova L.Ya. "A selfinstruction manual on the design and modeling of clothing", Moscow 1991, the company "Lyubaks", 65p.

3. Krasnikova - Aksenova L.Ya. "Cut without secrets”, 2007 - M. NOU, Lubaks ”, 302 p., 1075 il

4. Rossolimo T. The growth and development of the human body: 1962

5. Scheme of age-related periodization of human ontogenesis, adopted at the VII All-Union Conference on the problems of age-related morphology, physiology and biochemistry of the USSR Academy of Pedagogical Sciences (Moscow, 1965)

6. Standartinform. Typical figures of boys. Dimensional signs. 2006.100 s.

7. Standartinform. Moscow. Typical figures of men. Dimensional signs. 2005.27 p.

8. Startseva N. Maternity at risk, or Aggressive obstetric vandalism [Electronic resource] // Materials of the IV International Congress "Young Generation of the XXI Century: Actual Problems of Social and Psychological Health", September 22-24, 2009, Kirov. URL:

http://www.medicusamicus.com/index.php?action=4x 2171x1 (accessed date: (01.013. 2020).

9. Savelyeva G.M. Management of physiological and complicated births. Obstetrics and gynecology. 2011. - No. 3. - C. 4-10.

10. Thousand OV OPTIMIZATION OF TACTICS FOR PREGNANCY, CHILDBIRTH AND PERINATAL OUTCOMES IN HARVESTED PREGNANCY. The dissertation for the degree of candidate of medical sciences. Moscow - 2017

11.Shershneva L.P. Piryazeva T.V. Larkina L.V. Fundamentals of human morphology and biomechanics M. 2010

12. TSNIISHP Moscow Typical figures of girls. Dimensional signs. 2004.98 p.

13. TsNIISHP. Moscow Typical figures of women. Dimensional signs. Moscow. 2003.107 s 